\title{
Analisis Prestasi Mesin Motor Bakar Diesel Type Pauss Model 175A Untuk Bahan Bakar Solar Dan Bio Solar
}

\author{
Muchlisinalahuddin \\ Dosen Teknik Mesin Fakultas Teknik UMSB
}

\begin{abstract}
Abstrak: Ada beberapa faktor yang mempengaruhi energi yang dihasilkan oleh proses pembakaran yaitu kualitas dan kuantitas bahan bakar dan udara yang masuk ke dalam silinder, sistem penyalaan di dalam ruang bakar, dan kondisi temperatur ruang bakar. Untuk mengetahui seberapa besar energi yang dihasilkan oleh bahan bakar, maka perlu dilakukan pengujian dan pengukuran.

Pengujian dan analisis dilakukan pada alat uji motor bakar diesel empat langkah satu silinder daya 7,5 HP dengan pemberian beban bervariasi pada tuas rem tromol dan bahan bakar dengan nilai oktan yang berbeda.

Dari pengujian yang dilakukan dapat disimpulkan Penambahan beban akan mempengaruhi putaran $(\mathrm{rpm})$, waktu (s), daya (watt), torsi $(\mathrm{Nm})$ dan konsumsi bahan bakar (ml/s). Semakin besar daya yang dihasilkan maka konsumsi bahan bakar juga semakin besar.Bahan bakar bio solar lebih baik dibandingkan bahan bakar solar. Karena putaran mesin dan daya yang dihasilkan oleh bahan bakar bio solar lebih tinggi dari pada bahan bakar solar, sedangkan untuk konsumsi bahan bakar, bahan bakar bio solar lebih rendah dari pada bahan bakar solar.
\end{abstract}

Kata kunci : Prestasi mesin, unjuk kerja, motor bakar solar, solar, bio solar.

\section{PENDAHULUAN}

Motor bakar pembakaran dalam (internal combustion) merupakan salah satu jenis mesin penggerak yang banyak digunakan di dunia. Terutama untuk kendaraan tranportasi.Dimana terjadi perubahan perubahan energi, pembakaran / reaksi kimia yang menaikan tekanan . Peningkatan tekanan di manfaatkan untuk menggerakan piston yang berubah menjadi energy mekanik/ gerak. Pada penelitian ini dilakukan analisis terhadap energy perbandingan gerak berupa torsi, daya, laju aliran bahan bakar, dan putaran pada poros yang bisa dimanfaatkan di dalam energy mekanik / gerakan putaran yang dihasilkan dalam pengukuran. Torsi dilakukan dengan menhubungkannya dengan rem tromol (drum brake ) yang di tekan oleh beban tuas .beban yang di berikan bervariasi akan menghasilkan torsi yang berbeda . pengujian dilakukan membuat instalasi motor diesel pauss daya 7,5 HP. Dan selanjut nya di lakukan pengujian untuk bahan bakar Bio Solar dan Solar.

\section{TINJAUAN PUSTAKA}

\subsection{Teori Dasar Motor Diesel}

Mesin diesel adalah sejenis mesin pembakaran dalam; lebih spesifik lagi, sebuah mesin pemicu kompresi, dimana bahan bakar dinyalakan oleh suhu tinggi gas yang dikompresi, dan bukan oleh alat berenergi lain (seperti busi).

Seorang penemu/peneliti bernama Street melakukan penelitiannya. Perkembangan motor pembakaran dalam (ICE) pada tahun 1794. Hasil dari perkembangan tersebut adalah motor diesel sekarang. Selanjutnya dikembangkan oleh seorang insinyur muda berkewarga negaraan Perancis yang bernama Sadi Carnet pada tahun 1824.

Idenya dijadikan dasar dalam perkembangan motor diesel. Dia menyatakan bahwa udara murni yang dimampatkan tersebut dengan perbandingan 15:1 akan menghasilkan udara yang panas untuk menyalakan kayu kering. Udara yang digunakan untuk pembakaran motor hendaknya dikompresikan dengan perbandingan yang besar sebelum dinyalakan. Dia juga menyatakan bahwa dinding silinder hendaknya didinginkan, karena panas dari dari pembakaran akan mempengaruhi kinerja motor.

Pada tahun 1876 Dr. Nickolas Otto mebuat konstruksi motor pembakaran dalam 4 langkah yang menggunakan bahan bakar bensin menggunakan penyalaan api. Pada 
tahun 1892 seorang insinyur muda berkewarganegaraan German yang bernama Dr. Rudolf Diesel berhasil membuat motor penyalaan kompresi menggunakan bahan bakar serbuk batu bara menggunakan prinsip penyalan bahan bakar dan udara.

Dengan perkembangan sistem pompa injeksi bahan bakar yang benar-benar dapat disebut "mini" oleh seorang penemu yang berkewarganegaraan german bernama Robert Bosch pada tahun 1927 membebaskan motor diesel dari masalah memakan tempat. Sistem injeksi pompa Robert Bosch yang ukurannya mini dari karburator, beratnya ringan dan governer yang menyatu (built-in) sehingga tidak ada lagi sistem pengabutan udara yang banyak makan tempat untuk kompresor, pipapipa dan pengontrol klep. Pompa injeksi motor diesel dapat diatur sesuai pembebanan, sedangkan kondisi kecepatan motor dapat atau lebih baik dari karburator motor bensin. Prinsip kerja motor diesel adalah merubah energi kimia menjadi energi mekanis. Energi kimia didapatkan melalui proses reakasi kimia (pembakaran) dari bahan bakar (solar) dan oksidiser (udara) di dalam silinder (ruang bakar).

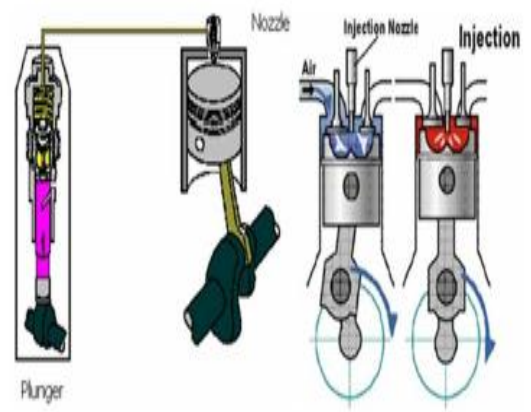

Gambar 2.1. Prinsip kerja motor diesel

Pada motor diesel ruang bakarnya bisa terdiri dari satu atau lebih tergantung pada penggunaannya dan dalam satu silinder dapat terdiri dari satu atau dua torak. Pada umumnya dalam satu silinder motor diesel hanya memiliki satu torak.

Tekanan gas hasil pembakaran bahan bakan dan udara akan mendorong torak yang dihubungkan dengan poros engkol menggunakan batang torak, sehingga torak dapat bergerak bolak-balik (reciprocating). Gerak bolak-balik torak akan diubah menjadi gerak rotasi oleh poros engkol (crank shaft). Dan sebaliknya gerak rotasi poros engkol juga diubah menjadi gerak bolak-balik torak pada langkah kompresi.

Berdasarkan cara menganalisa sistim kerjanya, motor diesel dibedakan menjadi dua, yaitu motor diesel yang menggunakan sistim airless injection (solid injection) yang di analisa dengan siklus dual dan motor diesel yang menggunakan sistim air injection yang dianalisa dengan siklus diesel (sedangkan motor bensin dianalisa dengan siklus otto).

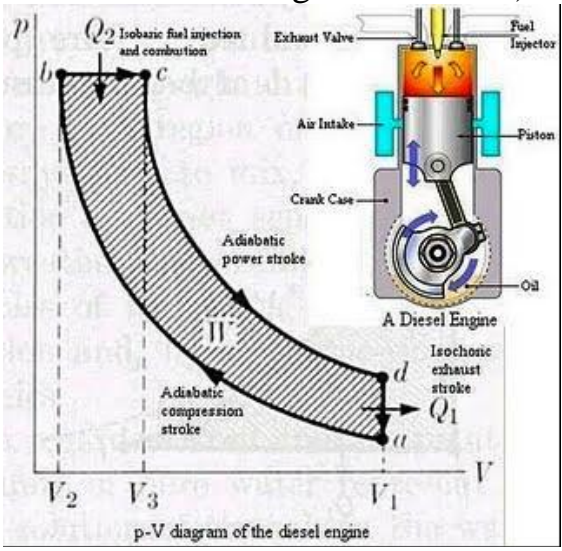

Gambar 2.2. Diagram P-V siklus diesel

Perbedaan antara motor diesel dan motor bensin yang nyata adalah terletak pada proses pembakaran bahan bakar, pada motor bensin pembakaran bahan bakar terjadi karena adanya loncatan api listrik yang dihasilkan oleh dua elektroda busi (spark plug), sedangkan pada motor diesel pembakaran terjadi karena kenaikan temperatur campuran udara dan bahan bakar akibat kompresi torak hingga mencapai temperatur nyala. Karena prinsip penyalaan bahan bakarnya akibat tekanan maka motor diesel juga disebut compression ignition engine sedangkan motor bensin disebut spark ignition engine.

Pada mesin diesel, dibuat"ruangan" sedemikian rupa sehigga pada ruang itu akan terjadi peningkata suhu hingga mencapai "titik nyala" yang sanggup "membakar" minyak bahan bakar. Pemampatan yang biasanya digunakan hingga mencapai kondisi "terbakar" itu biasanya 18 hingga 25 kali dari volume ruangan normal.

Ketika udara dikompresi suhunya akan meningkat (seperti dinyatakan oleh Hukum Charles), mesin diesel menggunakan sifat ini untuk proses pembakaran. Udara disedot ke 
dalam ruang bakar mesin diesel dan dikompresi oleh piston yang merapat, jauh lebih tinggi dari rasio kompresi dari mesin bensin. Beberapa saat sebelum piston pada posisi Titik Mati Atas (TMA) atau BTDC (Before Top Dead Center), bahan bakar diesel disuntikkan ke ruang bakar dalam tekanan tinggi melalui nozzle supaya bercampur dengan udara panas yang bertekanan tinggi. Hasil pencampuran ini menyala dan membakar dengan cepat. Penyemprotan bahan bakar ke ruang bakar mulai dilakukan saat piston mendekati (sangat dekat) TMA untuk menghindari detonasi.

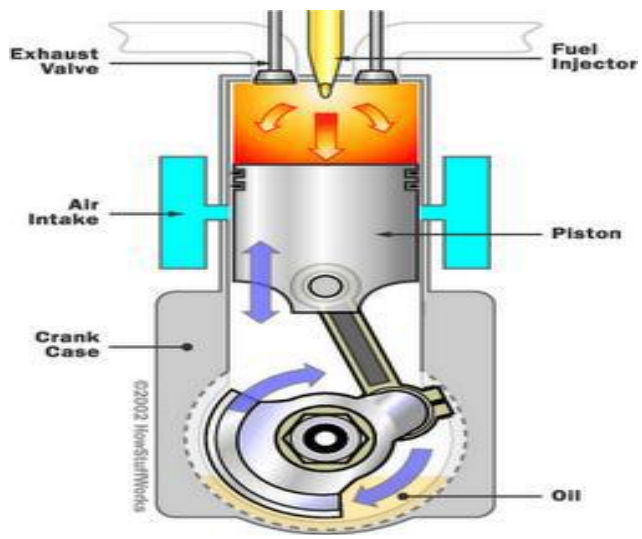

Gambar 2.3. Pembakaran pada motor diesel

Ledakan tertutup ini menyebabkan gas dalam ruang pembakaran mengembang dengan cepat, mendorong piston ke bawah dan menghasilkan tenaga linear. Batang penghubung (connecting rod) menyalurkan gerakan ini ke crankshaft dan oleh crankshaft tenaga linear tadi diubah menjadi tenaga putar. Tenaga putar pada ujung poros crankshaft dimanfaatkan untuk berbagai keperluan.

Untuk meningkatkan kemampuan mesin diesel, umumnya ditambahkan komponen :

- Turbocharger atau supercharger untuk memperbanyak volume udara yang masuk ruang bakar karena udara yang masuk ruang bakar didorong oleh turbin pada turbo/supercharger.

- Intercooler untuk mendinginkan udara yang akan masuk ruang bakar. Udara yang panas volumenya akan mengembang begitu juga sebaliknya, maka dengan didinginkan bertujuan supaya udara yang menempati ruang bakar bisa lebih banyak.

Mesin diesel sulit untuk hidup pada saat mesin dalam kondisi dingin. Beberapa mesin menggunakan pemanas elektronik kecil yang disebut busi menyala (spark/glow plug) di dalam silinder untuk memanaskan ruang bakar sebelum penyalaan mesin. Lainnya menggunakan pemanas "resistive grid" dalam "intake manifold" untuk menghangatkan udara masuk sampai mesin mencapai suhu operasi. Setelah mesin beroperasi pembakaran bahan bakar dalam silinder dengan efektif memanaskan mesin.

\section{Motor Diesel Empat Langkah}

Pada motor diesel empat langkah prinsip kerjanya untuk menyelesaikan satu siklus atau satu rangkaian proses kerja hingga menghasilkan pembakaran dan satu kali langkah usaha diperlukan empat langkah piston.

Langkah pertama adalah langkah pemasukan. Pada langkah ini yang dimasukkan kedalam silinder adalah udara murni. Katup masuk terbuka sedangkan katup buang tertutup. Piston bergerak dari TMA ke TMB. Langkah kedua adalah langkah kompresi. Kedua katup yaitu katup masuk dan katup buang sama-sama tertutup. Piston bergerak dari TMB ke TMA. Yang dikompresikan adalah udara murni.

Langkah berikutnya adalah langkah usaha. Proses pembakaran dan ekspansi merupakan langkah yang menghasilkan tenaga motor. Kedua katup yaitu katup masuk dan katup buang tertutup semuanya. Karena adanya proses pembakaran didalam silinder terjadilah kenaikan tekanan dan ekspansi dari gas (campuran udara dan bahan bakar). Piston didorong dari TMA ke TMB.

Langkah selanjutnya adalah langkah pembuangan. Piston bergerak dari TMB ke TMA. Katup buang terbuka sedangkan katup masuk tetap tertutup. Gas bekas hasil pembakaran didorong keluar oleh piston yang bergerak dari TMB ke TMA. Berikut adalah gambar dari prinsip kerja mesin diesel 4 langkah: 


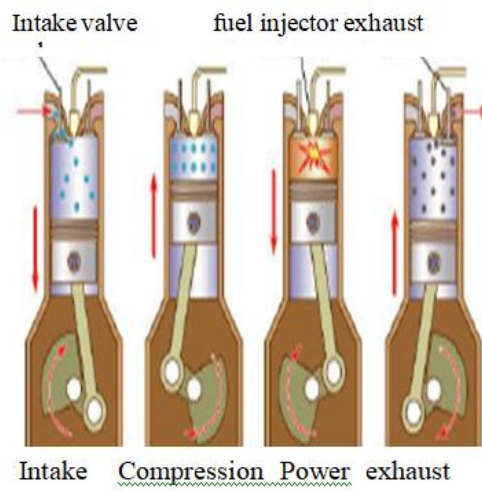

Gambar 2.4. Siklus Motor Diesel 4 Langkah

\subsection{Bahan Bakar Diesel}

Penggolangan bahan bakar mesin diesel berdasar kan jenis putaran mesinya ,dapat di bagi dua golongan yaitu :

a) Automotive diesel oil, yaitu bahan bakar yang di gunakan untuk mesin dengan kecepatan putaran mesi di atas $1000 \mathrm{rpm}$. Bahan bakar jenis ini yang biasa di gunakan sebagai bahan bakar diesel yang digunakan untuk kendaraan bermotor

b) Industrial Diesel Oil , yaitu bahan bakar yang digunakan untuk mesin - mesin yang mempunyai putaran mesin kurang atau sama dengan 1000 rpm, bisanya digunakan untuk mesin - mesin industri . bahan bakar ini disebut minyak diesel

Di Indonesia , bahann bakar untuk kendaraa motor jenis diesel umumnya menggunakan solar yang di produksi oleh PT. PERTAMINA dengan karakteristik seperti tabel di bawah ini

\section{Karakteristik Bio solar}

Bio solar / bio diesel tidak megandung nitrogen atau senyawa aromatic dan hanya mengandung kurang dari ppm ( part per million ) sulfur . bio diesel mengandung kira - kira $11 \%$ oksigen dalam persen berat yang keberadaannya mengakibatkan berkurangnya kandungan energy ( LHV menjadi lebih rendah bila di bandingkan dengan solar ) namun menurunkan kadar emisi gas buag yang berupa karbon monoksida (CO) ,hidro karbon (HC), partikulat dan jelaga. Kandungan energy bio diesel kira - kira $10 \%$ lebih rendah di bandigkan dengan solar.

\subsection{Dynamometer Pembebanan}

Dinamometer adalah sebuah alat yang digunakan untuk mengukur putaran mesin dan torsi dimana daya yang dihasilkan dari suatu mesin atau alat yang berputar dapat dihitung.

Pada prinsipnya dinamometer bekerja dengan cara memberikan beban kepada poros motor bakar melalui mekanisme pengereman pada poros engkolnya. Secara fungsional, dinamometer dirancang untuk digunakan pada motor bakar ukuran kecil dengan daya dibawah 10 HP.ada beberapa jenis dinamometer yang biasa digunakan yaitu dinamometer listrik dan dinamometer brakek Dalam penelitian ini dinamometer yang digunakan adalah dinamometer tipe brake, dimana cara kerjanya adalah putaran poros dinamometer berasal dari putaran mesin yang ditransmisikan dengan menggunakan poros yang dihubungkan dengan belt, dan poros ditumpu menggunakan bearing. Pada bagian kedua ujung pangkal serta pada poros terdapat sistem pengereman menggunakan drum brake.

\section{METODOLOGI PENELITIAN}

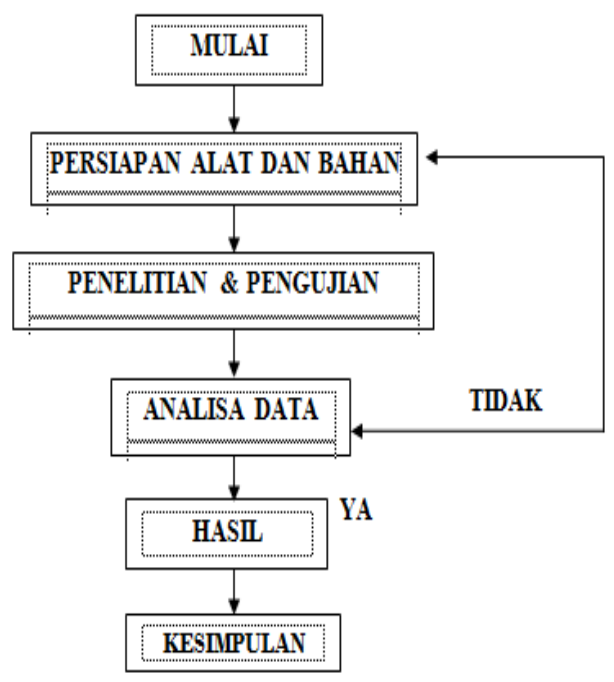

Gambar 3.1 diagram alir

\subsection{Alat dan Bahan}

- Alat uji motor bakar diesel

- Dynamometer

- Stopwacth

- Tabung ukur 
- Mistar

- Tachometer

- Massa atau beban

- Timbangan

- Bahan
O
Bahan bakar Solar
- Bahan bakar Bio Solar

\subsection{Prosedur Pengujian}

Adapun prosedur pengujian pada alat uji prestasi mesin motor bakar diesel ini dilakukan dengan urutan sebagai berikut.

A. Cek semua keadaan mesin dan peralatan yang akan di pakai.

B. Menghidupkan motor mesin diesel

1. On kan stop kontak pada mesin diesel.

2. Buka katup bahan bakar dan katup gas letakkan pada posisi terendah.

3. Putar poros engkol ke kanan. Kemudian lepaskan dekompresi jika mesin sudah hidup maka lepaskan engkol tangan tadi, maka akan kembali sendiri.

C. Pengujian

1. Beban bervariasi, putaran kutup berubah.

2. Menentukan daya putaran mesin

3. Menentukan konsumsi bahan bakar.

D. Untuk berbagai kondisi operasi mesin dilakukan pengamatan terhadap parameter-parameter atas

E. Data pengujian yang didapat diolah dan dibuat analisa dan perhitungannya terhadap pengujian tersebut

\section{ANALISIS DAN DATA}

\subsection{Data Bahan bakar Solar}

Percobaan diatas pada bahan bakar solar di lakukan 8 kali uji dimana pemberian beban yang bervariasi antara $0 \mathrm{~s} / \mathrm{d} 1500$ gram pada volume bahan bakar konstan atau tetap pada $25 \mathrm{ml}$. Pada pengujian ini dapat di lihat laju bahan bakar $(\mathrm{ml} / \mathrm{s})$, torsi $(\mathrm{Nm})$, daya ( watt), dan rpm .pada pengujian bahan bakar solar dimana beban yang ber variasi dapat mempengaruhi putaran mesin pada volume bahan bakar yang konstan atau tetap. bahwa semakin besar beban yang diberikan maka semakin menurun putaran karena beban yang diberi, semakin menurun putaran maka konsumsi bahan bakar semakin besar .

\subsection{Data bahan bakar Bio Solar}

Tabel 4.1 Data Pengujian Bio Solar

\begin{tabular}{|c|c|c|c|c|c|c|c|c|c|}
\hline \multirow[t]{2}{*}{ No } & \multirow{2}{*}{\begin{tabular}{|c|} 
beban \\
[gr]
\end{tabular}} & \multirow{2}{*}{$\begin{array}{c}\mathrm{T} \\
{[\mathrm{Nm}]}\end{array}$} & \multirow{2}{*}{$\begin{array}{c}\mathrm{P} \\
\text { [Watt] }\end{array}$} & \multirow{2}{*}{$\begin{array}{r}\text { Bbm } \\
{[\mathrm{mll}]}\end{array}$} & \multicolumn{3}{|c|}{ Waktu(s) } & \multirow{2}{*}{$\begin{array}{l}\mathrm{Bbm} \\
{[\mathrm{ml} / \mathrm{s}]}\end{array}$} & \multirow[b]{2}{*}{$\mathrm{rpm}$} \\
\hline & & & & & menit & Detik & $\begin{array}{c}\text { total } \\
{[\mathrm{s}]}\end{array}$ & & \\
\hline 1 & 0 & 0 & 0 & 25 & 4 & 56 & 296 & 0.084459 & 1662 \\
\hline 2 & 500 & 2.4525 & 416.5705 & 25 & 4 & 32 & 272 & 0.091912 & 1622 \\
\hline 3 & 650 & 3.18825 & 533.1948 & 25 & 4 & 18 & 258 & 0.096899 & 1597 \\
\hline 4 & 800 & 3.924 & 645.5558 & 25 & 3 & 54 & 234 & 0.106838 & 1571 \\
\hline 5 & 950 & 4.65975 & 746.1029 & 25 & 3 & 38 & 218 & 0.114679 & 1529 \\
\hline 6 & 1100 & 5.3955 & 848.0882 & 25 & 3 & 9 & 189 & 0.132275 & 1501 \\
\hline 7 & 1250 & 6.13125 & 943.1905 & 25 & 2 & 52 & 172 & 0.145349 & 1469 \\
\hline 8 & 1500 & 7.3575 & 1084.059 & 25 & 2 & 35 & 153 & 0.163399 & 1407 \\
\hline
\end{tabular}

Percobaan diatas pada bahan bakar bio solar di lakukan 8 kali uji dimana pemberian beban yang bervariasi antara $0 \mathrm{~s} / \mathrm{d}$ 1500 gram pada volume bahan bakar konstan atau tetap pada $25 \mathrm{ml}$. Pada pengujian ini dapat di lihat laju bahan bakar ( $\mathrm{ml} / \mathrm{s}$ ), torsi ( $\mathrm{Nm}$ ), daya (watt), dan rpm .pada pengujian bahan bakar solar dimana beban yang ber variasi dapat mempengaruhi putaran mesin pada volume bahan bakar yang konstan atau tetap. bahwa semakin besar beban yang diberikan maka semakin menurun putaran karena beban yang diberi, semakin menurun putaran maka konsumsi bahan bakar semakin besar.

\subsection{Data perbandingan bahan bakar Solar dengan Bio Solar}

Tabel pembahasan bahan bakar solar dengan bio solar. Pembahasan ini berdasarkan putaran yang di hasilkan dari kedua bahan bakar tersebut . 
Tabel 4.2 Solar

\begin{tabular}{|l|r|r|c|c|r|r|}
\hline No & \multicolumn{1}{|c|}{ Daya } & $\begin{array}{r}\text { Bbm } \\
25 \mathrm{ml}\end{array}$ & $\begin{array}{c}\dot{\mathrm{m}} \text { bbm } \\
\mathrm{ml} / \text { det }\end{array}$ & $\begin{array}{c}\text { Waktu } \\
(\mathrm{s})\end{array}$ & $\begin{array}{c}\text { Rpm } \\
2 \pi 60 \text { det }\end{array}$ & \multicolumn{1}{c|}{ Putaran } \\
\hline $\mathbf{1}$ & 0 & 25 & 0.092251 & 271 & 1660 & 7497.667 \\
\hline $\mathbf{2}$ & 406.0406403 & 25 & 0.099206 & 252 & 1581 & 6640.2 \\
\hline $\mathbf{3}$ & 516.5011586 & 25 & 0.104603 & 239 & 1547 & 6162.217 \\
\hline $\mathbf{f}$ & 615.558638 & 25 & 0.120773 & 207 & 1498 & 5168.1 \\
\hline $\mathbf{5}$ & 702.6737456 & 25 & 0.138122 & 181 & 1440 & 4344 \\
\hline $\mathbf{6}$ & 787.6315216 & 25 & 0.152439 & 164 & 1394 & 3810.267 \\
\hline $\mathbf{7}$ & 869.9953631 & 25 & 0.178571 & 140 & 1355 & 3161.667 \\
\hline $\mathbf{8}$ & 1009.323034 & 25 & 0.219298 & 114 & 1310 & 2489 \\
\hline
\end{tabular}

Tabel 4.3 Bio Solar

\begin{tabular}{|l|r|r|c|r|r|r|}
\hline No $_{0}$ & Daya & $\begin{array}{c}\text { Bbm } \\
25 \mathrm{ml}\end{array}$ & $\begin{array}{c}\dot{\mathrm{m}} \text { bbm } \\
\text { ml/det }\end{array}$ & $\begin{array}{c}\text { Waktu } \\
(\mathrm{s})\end{array}$ & $\begin{array}{c}\text { Rpm } \\
2 \pi 60 \text { det }\end{array}$ & \multicolumn{1}{c|}{ Putaran } \\
\hline $\mathbf{1}$ & 0 & 25 & 0.084459 & 296 & 1662 & 8199.2 \\
\hline $\mathbf{2}$ & 416.5704735 & 25 & 0.091912 & 272 & 1622 & 7353.067 \\
\hline $\mathbf{3}$ & 533.1947965 & 25 & 0.096899 & 258 & 1597 & 6867.1 \\
\hline $\mathbf{f}$ & 645.5558213 & 25 & 0.106838 & 234 & 1571 & 6126.9 \\
\hline $\mathbf{5}$ & 746.1028869 & 25 & 0.114679 & 218 & 1529 & 5555.367 \\
\hline $\mathbf{6}$ & 848.0881736 & 25 & 0.132275 & 189 & 1501 & 4728.15 \\
\hline $\mathbf{7}$ & 943.1905449 & 25 & 0.145349 & 172 & 1469 & 4211.133 \\
\hline $\mathbf{8}$ & 1084.059167 & 25 & 0.163399 & 153 & 1407 & 3587.85 \\
\hline
\end{tabular}

Pada tabel perbandingan di atas dimana cara metode pengambilan data dilakukan dengan cara yang sama dan volume bahan bakar sama konstan $25 \mathrm{ml}$ dan pemberian beban sama dilakukan sebanyak 8 kali secara bertingkat antara $0 \mathrm{~s} / \mathrm{d} 1500$ gram .

Dimana setiap tingkatan pemberian beban di lakukan maka daya yang di dapat semakin besar ,laju aliran bahan bakar semakin besar, rpm semakin turun dan putaran/ radius semakin kecil terhadap volume bahan bakar $25 \mathrm{ml}$

\section{SIMPULAN DAN SARAN}

Dari hasil alat uji prestasi mesin motor bakar diesel yang telah dilaksanakan dapat di tarik kesimpulan antara lain;

1. Penambahan beban akan menurunkan putaran (rpm) dan daya yang di hasil oleh bahan bakar Bio solar lebih tinggi dari bahan bakar solar

2. Semakin besar daya yang di perlukan maka konsumsi bahan bakar juga semaki besar, kenaikan bahan bakar solar lebih tinggi dari bahan bakar bio solar
3. Penurunan putaran terhadap konsumsi bahan bakar pada bahan bakar bakar mesin solar lebih tinggi dari bahan bakar mesin bio solar

4. Daya yang di hasilkan oleh bio solar lebih tinggi dari solar untuk torsi yang sama

5. Jumlah putaran yang di hasilkan untuk $25 \mathrm{ml}$ bahan bakar mesin bio solar lebih tinggi dari bahan bakar mesin solar

Dari hasil Analisis data alat uji pretasi mesin motor bakar diesel yang telah dilaksanakan ada beberapa yang perlukan di perhatikan antara lain;

1. Disarankan agar alat uji motor bakar diesel dapat dilakukan dengan merubah parameter lain seperti ratio kompresi ,setelan katub dan lain - lain.

2. Pengambilan data sebaik nya di lakukan di ruangan yang terbuka, karena alat uji motor bakar diesel gas pembuangan nya sangat berpotensi untuk kesehatan untuk si peneliti

\section{DAFTAR PUSTAKA}

Arismunandar,wiranto dan Koichi Tsuda, Motor diesel putaran Tinggi, Jakarta ,1976 dan Pradnya Paramita 1980 motor bakar.

Ir Sadi Carnet, prancis pada tahun 1824. Pengembangan motor bakar diesel

Joni Dewanto dan Sugando Wibowo,2007 ,pengaruh gerak relatife sepatu terhadap efektifitas pengereman pada jenis rem tromol

Karnowo ,Winarno,Basyirun ,2008,mesin konversi energi universitas semarang

Nakoela Soenarta ,Shoichi fururhama.1995 motor bakar serba guna. 